\title{
Antioxidant activity of polyoxometalates
}

\author{
Farkhanda Nawaz ${ }^{1}$, Kausar Malik ${ }^{2 *}$ Muhammad Hamza Basit ${ }^{2}$ and \\ Husnain Qamar ${ }^{2}$ \\ 1. Lahore College for Women University, Jail Road Lahore-Pakistan \\ 2. National Center of Excellence in Molecular Biology, University of the Punjab 87-West Canal Bank \\ Road,ThokarNiazBaig Lahore-53700-Pakistan \\ *Corresponding author's email:kausarbasit786@yahoo.com \\ Citation \\ Farkhanda Nawaz, Kausar Malik, Muhammad Hamza Basit and Husnain Qamar. Antioxidant activity of \\ polyoxometalates. Pure and Applied Biology. Vol. 8, Issue 1, pp667-671. \\ http://dx.doi.org/10.19045/bspab.2019.80006
}

Received: 14/11/2018 Revised: 09/01/2019

Accepted: $12 / 01 / 2019$

Online First: 18/01/2019

\section{Abstract}

Spectrophotometer was used to estimate the antioxident action of Polyoxometalates (POMs;silicovanadate and iron substituted phosphotungstate) for various fixations and contrast, ascorbic acid utilization as standard.POMs have pulled in enthusiasm from an assortment of controls, and the applications in the fields of chemical investigation, catalysis, material science, atomic waste treatment, and drug are created. Three fixations were made $150 \mu \mathrm{g} / \mathrm{ml}, 100 \mu \mathrm{g} / \mathrm{ml}$ and $50 \mu \mathrm{g} / \mathrm{ml}$. Antioxidant activity was measured as free radical scavenging activity by spectrophotometer.Estimated antioxidant activity of silicovanadate was as $4.5 \pm 0.763,15 \pm 1$ and $25.5 \pm 0.72$ for three concentrations individually. The measured figuresof antioxidant activity of ironosubstitutedphosphotungstate were $1.2 \pm 0.529,13 \pm 1$ and $20 \pm 1$ for three concentrations individually.Antioxidative action proposes its promising applications as a characteristic antioxidant cell for the treatment and counteractive action of free radicals related maladies.

Keywords: Antioxidant; Phosphotungstate; Polyoxoometalates; Silicovanadate

\section{Introduction}

Some transition metals are crucial for the typical working of living creatures.Some transition Metallo-drugs are turning into a fascinating exploration zone after the disclosure of cisplatin, Since at that point, numerous buildings have been incorporated and tried on numerous natural frameworks. Copper buildings are known to have an expansive range of organic activity [1]. The chemical nature of vanadium relationship with multidentate ligands has accomplished a unique noteworthiness in the most recent decade in light of its synergistic and therapeutic information [2]. POMs are an anionic bunch of early progress metals, for example, tungsten (W), molybdenum (Mo), vanadium $(\mathrm{V})$, niobium $(\mathrm{Nb})$, antimony $(\mathrm{Sb})$ and so forth., and oxygen, framed by the selfget together procedures [3]. These POMs show assortment of sizes, structures, high solvency in water, electrochemical movement and amalgamation of metals, which makes them a viable class of inorganic bunches [4] .Hetroatomicoxometalate ,a name was given to these compunds by Pope [5].These mixes are group compose with metal-oxygen and metal-oxygen-metal linkages with an extensive number of grid water in the interstitial position. Any component can be consolidated into the system of polyoxometalates[6]. Be that as it may, their insecurity at physiological $\mathrm{pH}$, nonspecific authoritative, and high 
harmfulness keep their utilization in natural sciences and uses of prescription. The present examination is intended to break down the atioxident activity of Polyoxometalates. It is ease and easy to study and achieve impressive and huge conclusions. By keeping every huge component, potential exercises and viable points of view of POMs under thought the present examination is wanted to think about free radical rummaging action of silicovanadate.Antioxidative action of siicovanadate recommends its promising applications as a characteristic antioxidative agent and wellbeing advancing operator for the treatment and anticipation of free radicals related ailments and it has natural properties that advance human wellbeing and help diminish the danger of incessant illness.

\section{Materials and methods}

\section{Synthesis of compounds}

Silicovanadate was orchestrated by the accompanying strategy

$5.85 \mathrm{~g}$ of sodium metavanadate was included $120 \mathrm{ml}$ of refined water and blended energetically at a rate of $1.04 \mathrm{~g}$ of TEOS (Tetraethyl Orthosilicate a silica source) was included dropwise into the above arrangement. An orange shading arrangement showed up when $\mathrm{pH}$ was changed in accordance with 3.5 by acidic acid. $\quad 0.5 \mathrm{M} \quad$ CTAB (Cetyltrimethylammonium bromide) was added to get yellow precipetates. percepitates were washed completely with refined water and left to dry at RT. Blended compound was marked.IronosubstitutedPhosphotungstate was integrated by the accompanying strategy in watery arrangement, change tungstin cations are composed by water $\left(\mathrm{H}_{2} \mathrm{O}\right)$, hydroxo $(\mathrm{OH}-)$ and oxo $\left(\mathrm{O}_{2-}^{-}\right)$ligands. The of a planned ligand parallels the charge of the metal cation. In this manner, the profoundly charged cations of completely oxidized metal, for example, tungsten (W) frame stable buildings with oxo ligands in watery basic arrangements (WO42-) in the relationship with iron and phosphate. On fermentation, a buildup response happens, which yields $\mathrm{M}-\mathrm{O}-\mathrm{M}$ spans. This procedure can be rehashed. The blended compound was named.

\section{DPPH radical scavenging capacity of the compounds}

The hydrogen particle or electron gift capacities of the relating POM (Silicovanadate) was estimated from the fading of the purple-colored methanol arrangement of 2,2-diphenylpicrylhydrazyl (DPPH).As a matter of first importance three distinct dilutions of compound were made $(150 \mu \mathrm{g} / \mathrm{ml}, \quad 100 \mu \mathrm{g} / \mathrm{ml}$ and $50 \mu \mathrm{g} / \mathrm{ml})$ in refined water.Two $\mathrm{ml}$ of various dilutions of the mixes in methanol were added to two $\mathrm{ml}$ of a $0.0094 \%$ methanol arrangement of DPPH. Trolox (1 mM) (Sigma-Aldrich), a steady antioxident, was utilized as an engineered reference.After a 30 min hatching period at room temperature, the absorbance was perused against a clear at $517 \mathrm{~nm}$. Restraint of free radical by DPPH in percent (I \%) was computed in following way: $\mathrm{I} \%=($ A blank - A sample $/$ A blank $) \times 100$ where A clear is the absorbance of the control response (containing all reagents with the exception of the test compound), and $\mathrm{A}$ sample is the absorbance of the test compound. Tests were done in triplicate.

\section{Results and discussion}

The cell reinforcement(antioxidant) limits of the silicovanadate as evaluated by free radical rummaging test are condensed in (Table $1 \&$ Figure 1; Table $2 \&$ Figure 2).

Cell reinforcements(antioxidant) through their searching force are helpful for the administration of those sicknesses. Radical that can acknowledge an electron or hydrogen radical to wind up plainly a stable diamagnetic atom. Antioxident movement of silicovanadate was more than iron substituted phosphotungstate and estimated as $25.5 \pm 0.72,15 \pm 1$ and $4.5 \pm 0.763$ and the readings were taken for iron substituted 
Phosphotungstate were $20 \pm 1,13 \pm 1$ and $1.2 \pm$ 0.529 for $15 \mathrm{mg} / \mathrm{ml}, 10 \mathrm{mg} / \mathrm{ml}$, and $5 \mathrm{mg} / \mathrm{ml}$ fixations separately. Every one of these readings were contrasted and ascorbic acid $(55 \pm 0.72)$ utilized as the standard.

DPPH stable free radical technique is a simple, fast a delicate method to overview the antioxidative agent movement of a particular compound[7]. Cell reinforcement movement of silicovanadate estimated were $4.5 \pm 0.763$, $15 \pm 1$ and $25.5 \pm 0.72$ for three dilutions separately. Every one of these readings were contrasted and ascorbic acid $(55 \pm 0.72)$ utilized as the standard.

In a comparative report which bolstered our outcomes where the absorbance of the Mo (VI)- PR-CTA complex at $612.0 \mathrm{~nm}$ was dissected against a clear reagent as the reference to assess the impact of segments of complex, for example, PR (pyrogallol red) and CTAC (N-cetyl-N-N-N-trimethyl ammonium particles) [8]. The absorption was expanded by expanding the PR concentration. At a steady fixation level of $0.05 \%(\mathrm{w} / \mathrm{v}) \mathrm{CTAC}$ and $100 \mathrm{ng} \mathrm{mL}-1$ of Mo, and the PR concentration in the scope of 3.0 $\times 10-6-1.2 \times 10-3 \mathrm{Mol} \mathrm{L}-1$. Furthermore, in spite of the present examination after that specific fixation, the absorbance remained around steady in a current report the antioxidant agent action of POM (silicovanadate) was expanded as expanded the centralization of the compound. The compound showed a measurement subordinate rummaging of DPPH radicals. The DPPH radical rummaging is a touchy antioxidant agent examine and is autonomous of substrate extremity. DPPH is a steady free. The reviewed literature revealed that POMs are rich both instructure and properties. The study of POMs is not only interesting in terms of the molecular structural diversity but also regarding the wide range of applications in catalysis, medicine and materials science. POMs reveal a large variety of shapes, sizes and compositions, from small to nanosized species, While biochemical and biological properties of POMs are subjects of increasing interest [9]. Due to their biological and biochemical effects, including antitumor, viral and -bacterial properties, POMs and POM-based systems are considered as promising future metallodrugs. Furthermore, from a medical point of view, membrane proteins represent the most important group of proteins/enzymes as their functions are vital for the survival of organisms. In this way, structure-activity relationships can be elaborated enabling the targeted synthesis of powerful POM-based antibiotic compounds [10].

Table 1.Perecntage inhibition of poms (silicovanadate) by DPPH radical scavenging activity

\begin{tabular}{|c|c|c|c|c|}
\hline \multirow{2}{*}{ S. No. } & & \multicolumn{3}{|c|}{ DPPH radical scavenging activity (\%age) } \\
\cline { 3 - 5 } & & $\mathbf{5 m g} / \mathbf{m l}$ & $\mathbf{1 0} \mathbf{m g} / \mathbf{m l}$ & $\mathbf{1 5} \mathbf{m g} / \mathbf{m l}$ \\
\hline 1 & Silicovanadate & $4.5,3.5,5.5$ & $14,16,15$ & $25.5,24.5,26.5$ \\
\hline 2 & Mean \pm STD & $4.5 \pm 0.763$ & $15 \pm 1$ & $25.5 \pm .72$ \\
\hline 3 & Ascorbic acid & $54,55,53$ & $55,54,56$ & $56,55,57$ \\
\hline & Mean \pm STD & $54 \pm 0.70$ & $55 \pm 0.70$ & $56 \pm 0.70$ \\
\hline
\end{tabular}




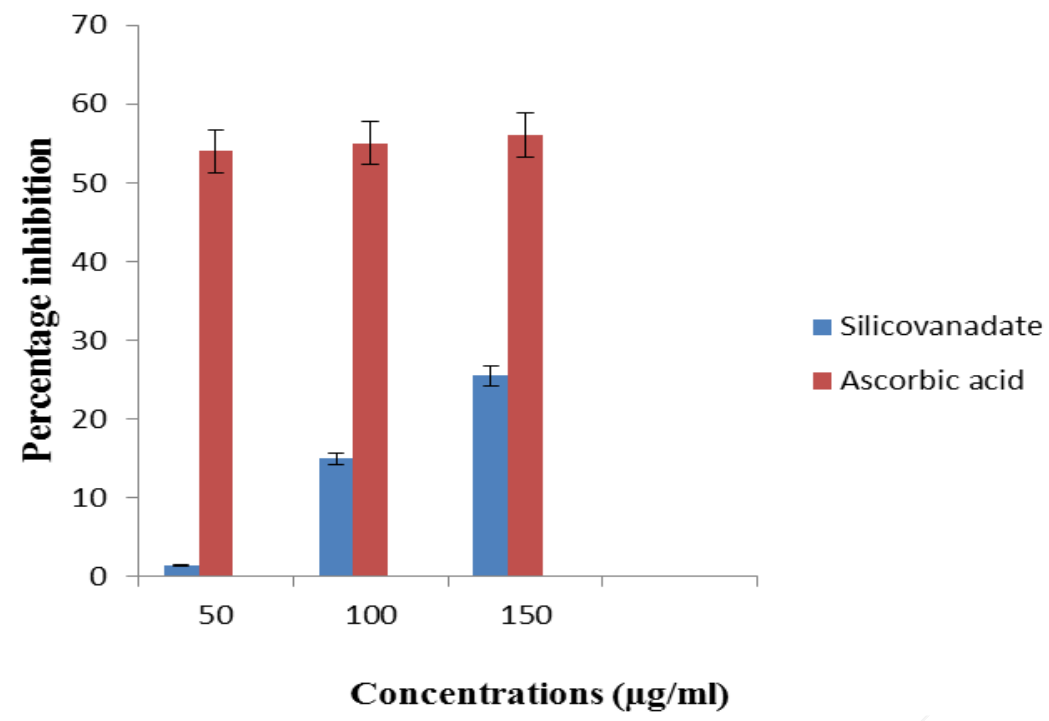

Figure 1. DPPH radical scavenging activity of POMs at different concentrations

Table 2. Perecntage inhibition of poms by DPPH radical scavenging

\begin{tabular}{|c|c|c|c|c|}
\hline \multirow{2}{*}{ S. No. } & & \multicolumn{3}{|c|}{ DPPH radical scavenging activity (\%age) } \\
\hline & & $50 \mu \mathrm{g} / \mathrm{ml}$ & $100 \mu \mathrm{g} / \mathrm{ml}$ & $150 \mu \mathrm{g} / \mathrm{ml}$ \\
\hline 1 & $\begin{array}{l}\text { Ironosubstituted } \\
\text { Phosphotungstate }\end{array}$ & $1.2,2.2,0.2$ & $13,14,12$ & $20,19,21$ \\
\hline 2 & Mean \pm STD & $1.2 \pm 0.529$ & $13 \pm 1$ & $20 \pm 1$ \\
\hline 3 & Ascorbic acid & $54,55,53$ & $55,54,56$ & $56,55,57$ \\
\hline & Mean \pm STD & $54 \pm 0.70$ & $55 \pm 0.70$ & $56 \pm 0.70$ \\
\hline
\end{tabular}

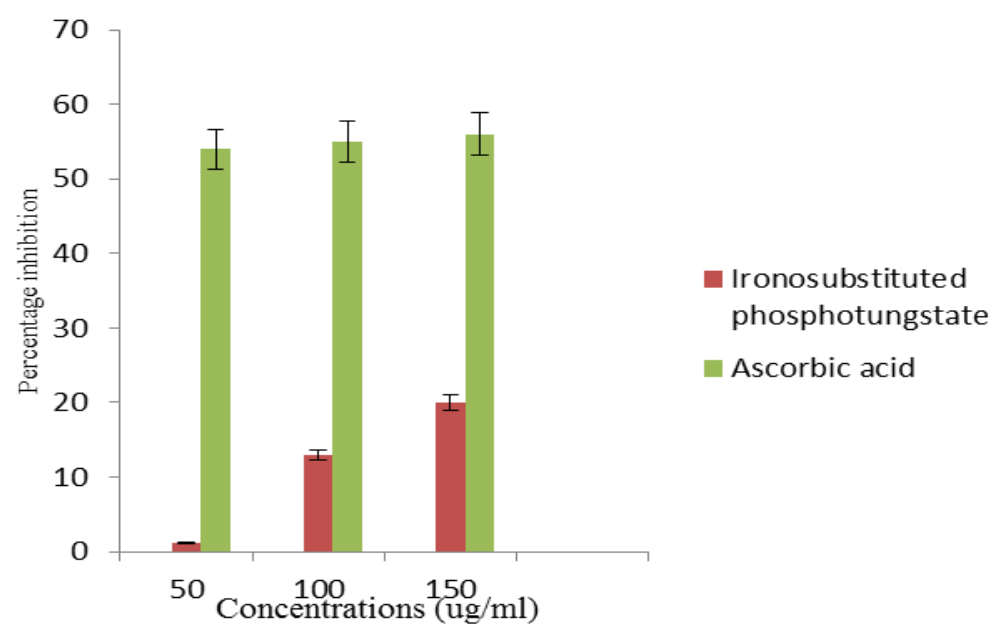

Figure 2. DPPH radical scavenging activity of POMs at different concentrations 


\section{Conclusion}

Polyoxometalates contain a wide assortment of antioxidant agents or bioactive atoms, which can kill the free radicals and accordingly hinder the advance of numerous, endless sicknesses related to oxidative pressure and reactive oxygen species (ROS). In the parent examine the DPPH scavenging impact (\%) of exacerbating The DPPH capacity of the sample was accounted for as the $\%$ of DPPH rummaging. A higher percent of DPPH rummaging corresponds to higher antioxidant activity. The activity of antioxidativeagent shows in the figures uncovers that cell reinforcement action was expanded as we expanded the convergences of the compound. Theuptake of natural antioxidant compounds has been related to decreased danger of malignancy, cardiovascular malady, diabetes and sicknesses related to maturing. Thus, the Silicovanadate might be abused as a characteristic antioxidant agent and wellbeing advancing specialist that can advantageously locate its fitting remedial applications.

\section{Authors' contributions}

Conceived and designed the experiments: $F$ Nawaz, K Malik, Performed the experiments: F Nawaz, Analyzed the data: F Nawaz, K Malik, Contributed materials/ analysis/tools: M H Basit, H Qamar, Wrote the paper: F Nawaz, K Malik.

\section{References}

1. Raman N, Johnson SR \& Sakthivel A (2009). Transition metal complexes with Schiff-base ligands 4-aminoantipyrine based derivatives-a review. $J$ of Coord Chem 62: 691-709.

2. Rehder D (2000).Vanadium nitrogenase. J of Inorg Biochem 80: 133-136.
3. Rhule JT, Hill CL, Judd DA \& Schinazi RT (1998). Polyoxometalates in Medicine. J of Coord Org Chem 98: 327-357.

4. Yamase T (2005). Anti-tumor, anti-viral and anti-bacterial activities of polyoxometalates for realizing an inorganic drug. J of Materials Chem15: 4773-4782.

5. Pope MT, Jeannin $\mathrm{Y} \&$ Fournier $\mathrm{M}$ (1983). Heteropoly and isopolyoxometalates. $J$ of Coord Org Chem 8: 250-258.

6. Fujita T, Fujita, Sakurai $\mathrm{T}$ \&Seto $\mathrm{Y}$ (1992).Anti-tumor,-viral, and-bacterial activities of polyoxometalates for realizing an inorganic drug. $J$ of Materials Chem 40: 173-176.

7. Koleva BT, Van A, Linsssen JPH \&Evstatieva LN (2002). Screening of extracts for antioxidant activity. $J$ of Pharma Sci 13: 8-17.

8. Gharehbaghi L, Maysam \& Farzaneh S (2011). Ionic liquid-based dispersive liquid-liquid microextraction and enhanced spectrophotometric determination of molybdenum (VI) in water and plant leaves samples by FOLADS. Food and Chem Tox 49: 423428.

9. Amman M (2013). Polyoxometalates: Formation, structures, principal properties, main deposition methods and application in sensing. $J$ of Materials Chem 1(21): 6291-6312.

10. Bijelic A, Aureliano M \& Rompel A (2018). The antibacterial activity of polyoxometalates: structures, antibiotic effects and future perspectives Chemical Communication (Camb). 54(10): 1531169. 